\title{
Intraocular Schwannoma
}

National Cancer Institute

\section{Source}

National Cancer Institute. Intraocular Schwannoma. NCI Thesaurus. Code C92182.

A benign schwannoma occurring in the eye. 